\title{
EFICIÊNCIA DE PRODUTO À BASE DE D-LIMONENO PARA O MANEJO DA COCHONILHA-DA-ROSETA-DO-CAFEEIRO PLANOCOCCUS CITRI EM CONDIÇÕES DE LABORATÓRIO
}

\author{
Luana Viana Faria ${ }^{1}$ \\ Alixelhe Pacheco Damascena ${ }^{2}$ \\ Cynthia Teixeira Vargas ${ }^{3}$ \\ Luis Moreira de Araújo Junior ${ }^{4}$ \\ Dirceu Pratissoli ${ }^{5}$
}

Resumo: A cochonilha-da-roseta-do-cafeeiro (Planococcus citri) consiste em um inseto praga capaz de onerar o custo de produção pelo uso excessivo de inseticidas sintéticos. Logo, percebe-se a necessidade de implementação de produto alternativo no manejo fitossanitário. O princípio ativo d-limonemo apresentase como um produto a ser testado pelo seu potencial inseticida, com toxidade reduzida ao ambiente. Logo, objetivou-se neste estudo analisar a atividade inseticida de $d$-limoneno em $P$. citri. Foi utilizado um produto comercial à base de d-limoneno nas seguintes concentrações: 6,25; 12,5; 25; 50; 100 e 200\% (v/v) a partir da recomendada pelo fabricante, aplicadas sobre dez ninfas de terceiro instar de $P$. citri presentes nas placas de Petri de $5 \mathrm{~cm}$ de diâmetro, contendo, em cada uma, um disco foliar do cafeeiro Coffea canephora cv Vitória, mantido sobre uma lâmina de ágarlágua a $1 \%(\mathrm{~m} / \mathrm{v})$. Verificou-se que os dados de mortalidade se ajustaram à análise de Probit, em que a concentrações mínimas testada 6,65\% e 133,49\% foram suficientes para se obter as concentrações letais CL50 e CL90, respectivamente. Portanto, conforme o parâmetro analisado, o d-limoneno constitui-se em uma alternativa a ser explorada no manejo de $P$. citri.

Palavras-chave: Produção; Potencial; Alternativa.

\footnotetext{
${ }^{1}$ Agronomia/Universidade Federal do Espirito Santo, Brasil. E-mail: Iuanavfaria@hotmail.com.

2 Agronomia/Universidade Federal do Espirito Santo, Brasil. E-mail: xellydamascena@hotmail.com.

3 Agronomia/Universidade Federal do Espirito Santo, Brasil. E-mail: cynthiatvargas@hotmail.com.

${ }^{4}$ Agronomia/Universidade Federal do Espirito Santo, Brasil. E-mail: luisjrmoreira@gmail.com.

${ }^{5}$ Agronomia/Universidade Federal do Espirito Santo, Brasil. E-mail: dirceu.pratissoli@gmail.com. 